INT. J. REMOTE SENSING, 1998, VOL. 19, NO. 9, 1663-1681

\title{
An assessment of satellite remotely-sensed land cover parameters in quantitatively describing the climatic effect of urbanization
}

\author{
T. W. OWEN $\dagger$, T. N. CARLSON and R. R. GILLIES $\ddagger$ \\ Department of Meteorology and Earth System Science Center \\ The Pennsylvania State University, University Park, PA 16802, USA
}

(Received 24 June 1996; in final form 3 September 1997)

\begin{abstract}
The regional-scale climatic impact of urbanization is examined using two land cover parameters, fractional vegetation cover (Fr) and surface moisture availability $\left(\mathrm{M}_{0}\right)$. The parameters are hypothesized to decrease as surface radiant temperature $\left(T_{0}\right)$ increases, forced by vegetation removal and the introduction of non-transpiring, reduced evaporating urban surfaces. $\mathrm{Fr}$ and $\mathbf{M}_{0}$ were derived from vegetation index and $\mathrm{T}_{0}$ data computed from the Advanced Very High Resolution Radiometer (AVHRR), and then correlated to a percentage of urban land cover obtained from a supervised classification of Landsat TM imagery. Data from 1985 through 1994 for an area near State College, PA, USA, was utilized.

Urban land cover change (at the rate of $>3$ per cent per $\mathrm{km}^{2}$ per year) was statistically significant when related to a decrease in normalized values of Fr and increase in normalized values of $\mathrm{T}_{0}$. The relationship between urbanization and $\mathrm{M}_{0}$, however, was ill-defined due to variations in the composition of urban vegetation. From a nomogram of values of Fr and $\mathrm{T}_{0}$, a Land Cover Index (LCI) is proposed, which incorporates the influence of local land cover surrounding urbanized pixels. Such an index could allow changes in land use at neighbourhoodscale to be input in the initialization of atmospheric and hydrological models, as well as provide a new approach for urban heat island analyses. Furthermore, the nomogram can be used to qualify urbanization effects on evapotranspiration rates.
\end{abstract}

\section{Introduction}

Over the past half century, the surface of the Earth has undergone substantial alteration due to anthropogenic activity, primarily through deforestation and urbanization. During this period, while rates of deforestation have varied broadly across the globe, there has been a nearly uniform explosion in the number of urban dwellers worldwide. The resultant expansion of urban land has important climatic implications across all scales, since the simultaneous removal of natural land cover and the introduction of urban materials (e.g., concrete, metal) alters the surface energy balance, with a consequent increase in sensible heat flux at the expense of latent heat flux (Stull 1988). Such re-partitioning of surface energy fluxes is often described by the Bowen ratio (the ratio of sensible to latent heat fluxes). Over highly evaporating surfaces (i.e., standing water), the Bowen ratio is approximately $0 \cdot 1$, while it can

$\dagger$ Current affiliation: National Climatic Data Center, Asheville, NC 28801, USA.

$\$$ Current affiliation: Department of Geography, and Department of Plants, Soils and Biometeorology, Utah State University, Logan, UT 84322, USA. 
exceed 1.0 over drier surfaces. Such an increase in the Bowen ratio invariably manifests itself in elevated temperatures at and above urban surfaces (Oke 1982).

The regional-scale climatic impact of urbanization has long been quantified by the so-called urban heat island (UHI), which emphasizes the disparity in ambient air temperature between urban and surrounding rural areas (Oke 1982). Unfortunately, the UHI is typically limited to a finite number of in situ temperature observations that describe the response rather than the forcing of repartitioned surface energy fluxes over urbanized surfaces. Furthermore, describing the UHI is becoming increasingly elusive as decentralization of urban areas across the globe obscures such a definitive distinction between urban and rural locales.

There has been a growing awareness concerning the sensitivity of atmospheric and hydrological models to 'meteorologically significant' land use change information, i.e., land use change that alters land cover and ultimately impacts ambient air temperature (Auer 1978, Balling and Brazell 1988, Roth et al. 1989), which is particularly apt in this era with the ever-increasing spatial resolution in these models. Such land use change data are also desirable for urban climate studies that attempt to quantify the climatic effect of encroaching urban development. Whether urban climate research emphasizes modelling or observation, it requires land cover information that accurately incorporates, in a consistent manner, urban land use and its associated surface energetic signature. Satellite remote sensing of the Earth's surface, despite its inherent vulnerability to atmospheric interference, is the most reliable and consistent means of monitoring land cover change associated with urbanization at the regional-scale, i.e., on the order of tens of kilometres. Such data is superior to in situ data from regional-scale field studies, which can be both costly to obtain at the appropriate resolution and vulnerable to private or governmental restriction (Henry et al. 1989). Moreover, the utility of satellite remote sensing is contingent upon the integration of high resolution satellite data to discern the complex texture of urban land cover that contributes to highly localized climatic responses (Nichol 1996).

Research over the past two decades shows that the partitioning of sensible and latent heat fluxes and, hence, surface radiant temperature response is modulated both by the surface soil water content (Idso et al. 1975) and vegetation cover (Goward et al. 1985, Nemani and Running 1989). Using satellite remote sensing over a region of varying surface soil water content and vegetation cover, Price (1990) found that predominantly bare soil locations experience a wider variation in surface radiant temperature than densely vegetated locations. This finding stimulated the development of new approaches (Carlson et al. 1994, Gillies and Carlson 1995) in the treatment of remotely-sensed data, later referred to as the 'triangle method' (Gillies and Carlson 1994, 1995): As shown in figure 1 (a schematic), a scatterplot of vegetation cover and surface radiant temperature for satellite remote sensed pixels results in a characteristic triangular-shaped envelope of pixels. The surface radiant temperature response along the abscissa is a function of varying vegetation cover and surface soil water content (which can be defined as a surface moisture availability). The darkened right edge of the schematic triangle is assumed to correspond to the physically-limiting maximum temperature at a given level of vegetation cover under completely dry soil conditions (that commensurate with a minimum extractable soil water content), and is termed the 'warm edge'.

Carlson et al. (1990) proposed a method for using satellite-derived values of surface radiant temperature $\left(\mathrm{T}_{0}\right)$ and the Normalized Difference Vegetation Index 


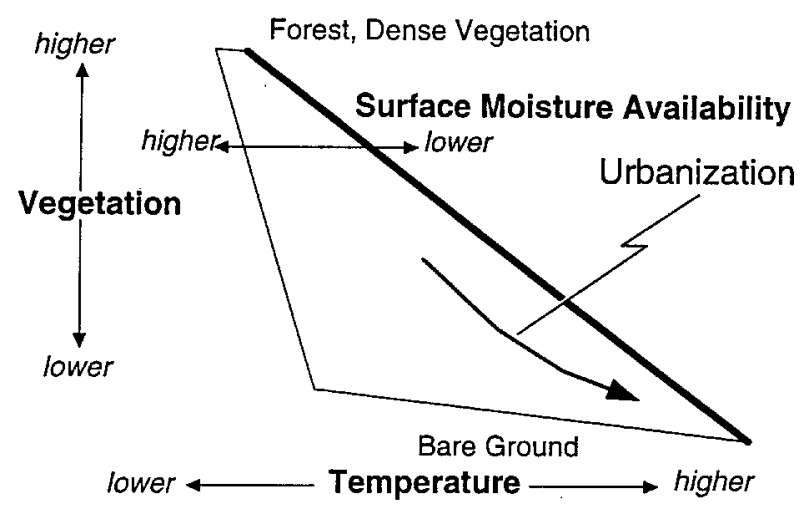

Figure 1. The 'triangle' scatterplot, showing the approximate extent of a hypothetical envelope of remotely-sensed pixels corresponding to a region containing a complete range of surface radiant temperature, vegetation cover and surface soil water content (surface soil moisture availability) values. The darkened right edge is the 'warm edge', and the arrow indicates the hypothesized migration of an urbanizing pixel.

(NDVI), in concert with simulations from an atmospheric boundary layer model with vegetation parameterization (a Soil-Vegetation-Atmosphere Transfer (SVAT) model), to derive two parameters, fractional vegetation cover (Fr) and surface soil water content, in terms of a surface moisture availability $\left(\mathbf{M}_{0}\right)$. By subjecting $\mathrm{T}_{0}$ and NDVI to a normalization procedure that minimized the uncertainties of the observations (due to surface and atmospheric variability) with output from a SVAT model, Gillies and Carlson $(1994,1995)$ demonstrated that the response of $\mathrm{T}_{0}$ to urbanization could be discerned in the context of a normalized, 'universal' triangle nomogram. Relating land cover statistics with values of $\mathrm{Fr}, \mathrm{M}_{0}$ and $\mathrm{T}_{0}$ requires the coupling of sub-pixel urban land cover data to pixel-wide values of $\mathrm{T}_{0}$ and NDVI. The former was attained through the Landsat TM sensor and the latter through the National Oceanic and Atmospheric Administration (NOAA) Advanced Very High Resolution Radiometer (AVHRR). While the Landsat sensor has a high resolution thermal infrared channel, it was not useful in this research because the satellite overpass did not occur when there was sufficient surface solar forcing to distinguish between urban and rural locales. Instead, thermal infrared data derived from the AVHRR was used, and Landsat TM data was used strictly for land cover classification.

In the context of the triangle nomogram, it is hypothesized that a surface location undergoing urbanization over time will usually experience an increase in $\mathrm{T}_{0}$ resulting from a reduction in both Fr and $\mathrm{M}_{0}$. The arrow in figure 1 illustrates this hypothesis, which shall be tested and conditionally verified in this paper. The trajectory in figure 1 assumes that urbanization takes place in a well-vegetated region. It is recognized that the trajectory can actually be reversed in highly arid regions where urbanization implies the replacement of barren land with irrigated grasses and ornamental trees (e.g., Phoenix, Arizona, USA; Palm Springs, California, USA). In this research, however, the most typical impact of urbanization on land cover is investigated, where the climatic response in $T_{0}$ is believed to be physically linked to the simultaneous removal of vegetation and the replacement of transpiring surfaces by those with considerably reduced evaporation. 


\section{Methodology}

2.1. Scene selection and geocoding

Figure 2 shows the location of the research study area, which encompasses a $1000 \mathrm{~km}^{2}$ region of Centre County, Pennsylvania, USA and includes the borough of State College. This study area was selected due to its limited size, tight land-use zoning, isolation from other metropolitan areas and convenient access for field verification of the results. Furthermore, with a growth rate of 9.8 per cent during the 1980s, Centre Country was a site where substantial urban development had
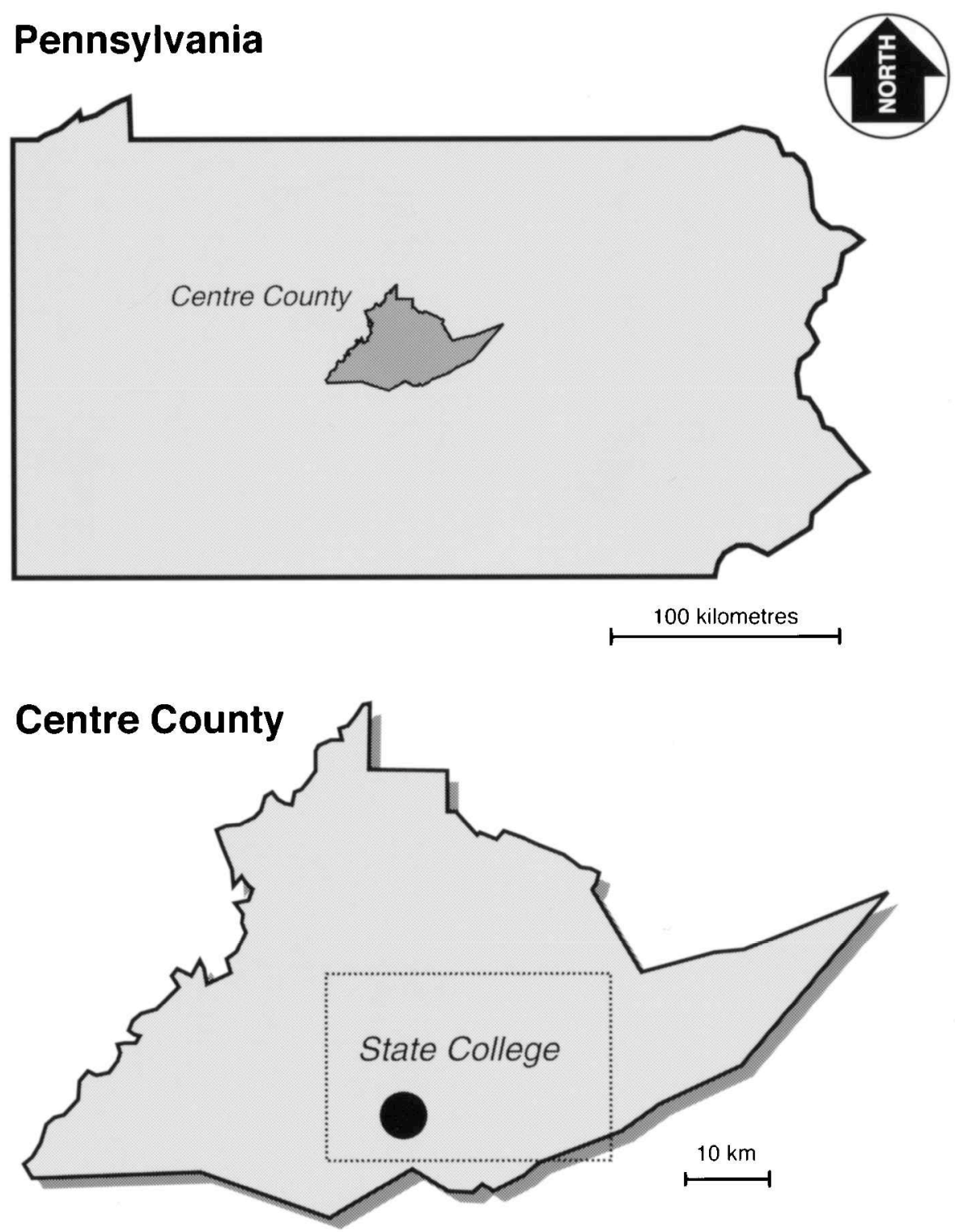

Figure 2. Location of the study area (indicated by the rectangular box), Southern Centre Country, Pennsylvania, USA 
taken place over the period in question (Centre Country Planning Office 1992). In light of this, eight AVHRR (in Level $1 \mathrm{~b}$ format) scenes were obtained for the study area from the U.S. Geological Survey's EROS Data Center - two single-date, Local Area Coverage (LAC) scenes each for the summers of 1985, 1988, 1991 and 1994. These scenes were selected to minimize both cloudiness and large viewing angles from nadir of the satellite; viewing angles were restricted to less than $40^{\circ}$ to minimize unacceptable errors in reflectance values in lieu of performing a rigorous correction for angular dependency of reflectance (Paltridge and Mitchell 1990). Given these criteria, coupled with the requirement that images be selected during the period of stable phenological conditions (from mid-June through mid-August) (Fisher 1994), a limited number of scenes were available for selection. As a result, it was not possible to completely avoid cloud and haze contaminated pixels in some scenes. Fortunately, such pixels were identified and excluded from the data analysis by using a modified cloud screening technique of Carlson et al. (1994). Once selected, the raw data for each of the eight AVHRR scenes was rectified and radiometrically corrected in order to assure a precise spatial and temporal inter-scene comparison (Emery et al. 1989).

Following the same broad criteria (e.g., cloud free overpasses) as for the AVHRR scenes, two Landsat TM scenes were used in this study — one from 1986 and another from 1993. The Landsat TM scenes were also geocoded through the application of additional processing algorithms. All image processing (for both the AVHRR and Landsat-TM scenes) was performed using the ERDAS $\otimes$ Imagine software package. These algorithms were required due to the different nature (e.g., terrain normalization) of the data.

\subsubsection{Image rectification}

A subset of each of the Landsat TM images (1986 and 1993) was taken to encompass the study area (figure 2) and subsequently rectified (resampled to $25 \mathrm{~m}$ resolution with a nearest neighbour algorithm) to Universal Transverse Mercator (UTM) coordinates. This method of resampling was also applied to the AVHRR data as maintaining the different and discrete levels of temperature was of primary importance, while in the case of the Landsat TM dataset nearest neighbour resampling is considered sufficient before any form of classification is undertaken.

In rectifying each AVHRR scene, a procedure was followed that was based on both instrument- and manually-derived ground truthing. First, a subset of each AVHRR scene was taken to include the mid-Atlantic region, encompassing the State of Pennsylvania. Next, the on-board ancillary location data (latitude and longitude) was used to fix Ground Control Points (GCPs) for each pixel, applied to each scene and resampled to a geographical (latitude/longitude) coordinate system at a resolution of $500 \mathrm{~m}$. Then, to compensate for inaccuracies in this data, associated with drift in the clock aboard the NOAA-N series of satellites (Emery et al. 1989), known physical features (i.e., coastlines, river bends, mountain ranges) were input as manual GCPs and each scene was again resampled to $500 \mathrm{~m}$ resolution geographical coordinates. Further image processing was applied to the AVHRR scenes by using the 1986 rectified Landsat-TM scene as the destination image for an image-to-image registration. Each AVHRR scene was subsequently subset to the vicinity of the study area and subjected to manual GCP selection based on known topographic features in the 1986 Landsat TM scene. From these GCPs, each AVHRR scene was subset precisely to the study area (now defined by the Landsat image) and resampled to UTM coordinates at a resolution of $1 \mathrm{~km}$, so that a single AVHRR pixel corresponded 
to a domain of 40 by 40 Landsat TM pixels. As a final check, all eight AVHRR scenes were compared against each other to assure a uniformly valid UTM registration. In each of the resampling steps for AVHRR, root mean square errors for the transformation matrices were less than $500 \mathrm{~m}$.

\subsubsection{Radiometric correction}

Radiometric correction was performed on each of the AVHRR scenes by first applying calibration coefficients provided in the ephemeris data, followed by additional algorithms. The ERDAS $\otimes$ Imagine image processor automatically applied ephemeris calibration values to the raw digital numbers for each of the five channels of the AVHRR instrument, yielding values of exoatmospheric reflectance (for channels 1 and 2) and at-sensor radiance (for channels 3, 4 and 5). In computing surface reflectance (i.e., correcting for the effects of atmospheric scattering, etc.) value for channels 1 and 2, a bulk haze correction was applied, based upon an offset that corresponded to the minimum reflectance value for each channel (Richards 1993). The at-sensor radiances for channels 4 and 5 were converted to at-sensor radiant temperatures using an empirical form of Planck's function given by equation (1).

$$
\mathrm{AST}_{\text {uncorr }}=\frac{c_{2} v}{\ln \left[\left(c_{1} v^{3}\right) / \beta\right]+1}
$$

where $c_{1}=1 \cdot 1910659 \mathrm{e}^{-5} \mathrm{~m} \mathrm{Wm} \quad \mathrm{Wm}^{-2} \mathrm{sr}^{-1} \mathrm{~cm}^{-4} ; \quad c_{2}=1.438833 \mathrm{~K} \mathrm{~cm}^{-1} ; \quad v=$ central wavenumber of channels 4 and $5 ; \beta=$ at-sensor radiance; $\mathrm{AST}_{\text {uncorr }}=$ uncorrected at-sensor temperature.

Next, a table of at-sensor radiant temperature corrections that addressed nonlinearities in the AVHRR instrument (NOAA 1988) were applied. Finally, surface radiant temperature was derived from the split window technique of Price (1984):

$$
\mathrm{T}_{0}=\mathrm{T}_{\mathrm{ch} 4}+3 \cdot 33 *\left(\mathrm{~T}_{\mathrm{ch} 4}-\mathrm{T}_{\mathrm{ch} 5}\right)
$$

where $T_{c h 4}$ and $T_{c h 5}$ are at-sensor values of radiant temperature for channels 4 and 5 of the AVHRR.

\subsection{Further data reduction-derivation of NDVI and land cover statistics}

The surface reflectance values for channels 1 (visible; $0.58-0.68 \mu \mathrm{m}$ ) and 2 (nearinfrared; $0 \cdot 72-1 \cdot 1 \mu \mathrm{m}$ ) of the AVHRR were input into the following equation to obtain values of NDVI:

$$
\mathrm{NDVI}=\frac{\alpha_{\mathrm{nir}}-\alpha_{\mathrm{vis}}}{\alpha_{\mathrm{nir}}+\alpha_{\mathrm{vis}}}
$$

where $\alpha$ is the surface reflectance and subscripts nir and vis correspond to channels 2 and 1 of the AVHRR, respectively. To facilitate an accurate temporal comparison between NDVI values from all AVHRR scenes, a sensor degradation correction was applied to all NDVI values, based on the number of months between satellite launch and scene overpass (Che and Price 1992). This corrected set of NDVI values was the final product used in the data analysis.

Land cover statistics were derived for both Landsat TM scenes (1986 and 1993). These scenes were initially subjected to a terrain normalization procedure that minimized solar illumination differences caused by topography (Hodgson and Shelley 1994). Then, a maximum likelihood supervised level I classification of the study area was performed according to Anderson et al. (1976). Five classes were distinguished- 
water, forest, agriculture, urban and unclassified and ground-truthed using the following - a 1990 EPA land cover map, Centre Country aerial photographs and expert knowledge from Centre County's Planning Office (Pennick 1995, private communication). The confidence of each pixel classification was evaluated using a spectral distribution of pixel variances from the mean of each class. Those pixels that exceeded a confidence interval threshold of 95 per cent using a Chi-square statistic were reclassified as unknown. From the five known classes, land cover statistics, that included the percentage of urban development for each AVHRR pixel, were compiled from a possible 1600 Landsat TM pixels corresponding to each AVHRR pixel.

\subsection{Normalization to the 'universal triangle' and derivation of land cover parameters}

A normalization procedure is required if an inter-comparison between AVHRR scenes is to take place. Without normalization, inter-scene variability in the state of the surface, the phenology of the vegetation and the condition of the atmosphere (e.g., haze, wind speed, humidity) prohibits such a comparison. The methodology for this procedure is illustrated by figure 3 , which is a scatterplot of $\mathrm{T}_{0}$ (obtained using equation (2)) and NDVI (obtained using equation (3)) for the 14 June 1994 AVHRR image. Solid circles represent cloud contaminated pixels, which tend to be localized at lower values of both NDVI and $\mathrm{T}_{0}$. As previously mentioned, these pixels were excluded from the analysis, leaving behind a triangular-shaped envelope of pixels.

Figure 3 also identifies four so-called 'anchor values' that were used to normalize the NDVI/ $T_{0}$ pixel envelope and create the universal triangle nomogram. The anchor values are designated according to their ability to describe accurately the full range of NDVI and $T_{0}$ values. In doing so, the validity of a hypothesis that the warm edge represents a minimum extractable soil water content is paramount.

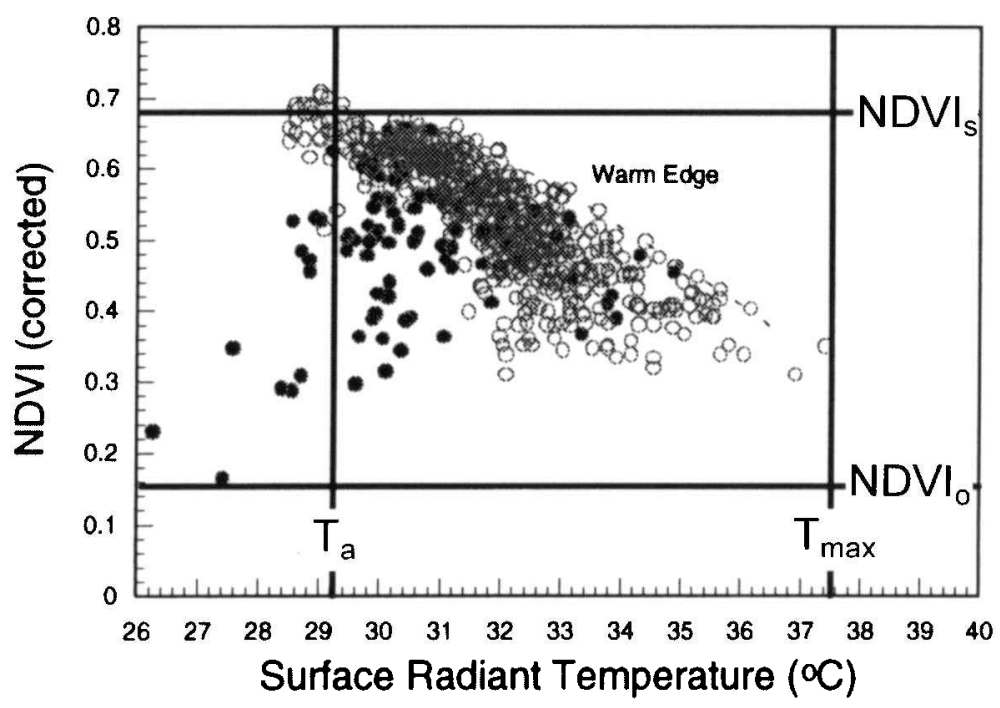

Figure 3. Scatterplot of NDVI versus $\mathrm{T}_{0}$ values from an AVHRR image of the study area, 14 June 1994. Pixels indicated by filled circles were cloud contaminated and excluded from further analysis. Normalization of the remaining triangular-shaped pixel envelope was accomplished using four 'anchor values', observed air temperature $\left(T_{a}\right)$, maximum warm edge temperature $\left(\mathrm{T}_{\max }\right)$, saturated NDVI $\left(\mathrm{NDVI}_{\mathrm{s}}\right)$ and bare soil NDVI $\left(\mathrm{NDVI}_{0}\right)$. 
As suggested by Gillies and Carlson (1995) and shown in figure 3, the warm edge tends to be sharply defined. In all the AVHRR scenes, the NDVI for 100 per cent vegetation cover $\left(\mathrm{NDVI}_{\mathrm{s}}\right)$ was identified at the point on the NDVI/T 0 envelope where the top begins to bend sharply to the left, signifying little further increase in NDVI with decreasing temperature. This choice of $\mathrm{NDVI}_{\mathrm{s}}$ is justified theoretically on the basis of radiative transfer calculations (not presented) and by other authors (e.g., Asrar et al. 1984, Gilabert et al. 1996 (their figure 11)) which show that, once the entire field of view is obscured by green vegetation, NDVI increases only slightly with increasing vegetation amount. At the opposite limit of NDVI, given that bare soil coverage over a $1 \mathrm{~km}^{2}$ domain of an AVHRR pixel is unlikely to be found in Pennsylvania during the growing season, bare soil NDVI $\left(\mathrm{NDVI}_{0}\right)$ was approximated from an average of regional metropolitan city centre NDVI values. Transformation of NDVI to a scaled NDVI $\left(\mathrm{N}^{*}\right)$ was accomplished using equation (4).

$$
\mathrm{N}^{*}=\frac{\mathrm{NDVI}-\mathrm{NDVI}_{0}}{\mathrm{NDVI}_{\mathrm{s}}-\mathrm{NDVI}_{0}}
$$

Temperature values were also scaled using attributes of the NDVI/ $\mathrm{T}_{0}$ pixel envelope. For a minimum temperature anchor value, observed ambient air temperature $\left(T_{a}\right)$ recorded at the Penn State meteorological observatory at the time of satellite overpass was used. For all eight AVHRR scenes analysed, $T_{a}$ approximately matched temperature values in a characteristic 'cusp' of pixels near the apex of the triangle, as shown in figure 3, despite inter-scene variability in the vicinity of the cusp. A maximum temperature anchor value $\left(T_{\max }\right)$ was selected by first fitting a second-order polynomial relations along the warm edge and then attaining the value of $T_{0}$ at the level of $\mathrm{NDVI}_{0}$. Despite the absence of AVHRR pixels in the vicinity of $\mathrm{NDVI}_{0}$, this method of selecting $\mathrm{T}_{\max }$ is justified given comparisons with higher resolution measurements (e.g., from the NS001 instrument), where completely bare soil pixels can be discerned at all levels of NDVI (Humes 1995, Carlson et al. 1995, Capehart 1996). Transformation to a scaled surface radiant temperature $\left(\mathrm{T}^{*}\right)$ was accomplished using equation (5):

$$
\mathrm{T}^{*}=\frac{\mathrm{T}_{\mathrm{s}}-\mathrm{T}_{\mathrm{a}}}{\mathrm{T}_{\max }-\mathrm{T}_{\mathrm{a}}}
$$

The normalized $\mathrm{N}^{*} / \mathrm{T}^{*}$ pixel envelope provides a relatively stable 'universal triangle' nomogram from which it is possible to derive certain intrinsic land cover parameters, in this case $\mathrm{Fr}$ and $\mathrm{M}_{0}$, using the approach of Gillies and Carlson (1995). Such a nomogram was coupled to simulated values of $\mathrm{Fr}$ and $\mathrm{M}_{0}$ derived from the SVAT model of the Penn State University Biosphere-Atmosphere Modeling Scheme (PSUBAMS) (Carlson and Boland 1978, Carlson et al. 1981, Lynn and Carlson 1990), which was initialized for the appropriate local ground conditions and meteorological conditions from the Mahantango watershed (located $100 \mathrm{~km}$ east of the study area).

The validity of coupling SVAT model output to the universal triangle nomogram $\left(\mathrm{N}^{*} / \mathrm{T}^{*}\right)$ relies on two fundamental relations. First, unstressed vegetation conditions are assumed, thereby establishing the non-linear relations between $\mathrm{Fr}$ and $\mathrm{N}^{*}$ $\left(\mathrm{Fr} \approx \mathrm{N}^{* 2}\right)$ (Choudhury et al. 1994, Gillies et al. 1997). The presence of a well-defined vertex near ambient air temperature confirmed the absence of significant plant stress in six of the eight AVHRR images (1988 excepted), since stressed vegetation yields 
a vertex that is diffuse toward higher temperature values. Second, as with the $\mathrm{NDVI} / \mathrm{T}_{0}$ pixel envelope, the warm edge of the $\mathrm{N}^{*} / \mathrm{T}^{*}$ nomogram is assumed to be the limiting edge of surface soil water content (i.e., $\mathrm{M}_{0}=0$ ). SVAT model simulations of bare soil temperature for the case of zero soil water content $\left(\mathrm{Fr}=0\right.$ and $\left.\mathrm{M}_{0}=0\right)$ matched $T_{\max }$, verifying the fundamental assumption that the warm edge is a physically-limiting edge of the pixel envelope. With these conditions assured, isopleths of $\mathrm{M}_{0}$ were derived for the full range of $\mathrm{N}^{*}$ and $\mathrm{T}^{*}$. These isopleths were overlaid on the nomogram using a third-order polynomial relations that, in essence, is a regionally applicable 'template' for all eight AVHRR scenes in the study.

Using land cover parameters Fr and $\mathrm{M}_{0}$, two scatterplots (figures $4(a)$ and $(b)$ ) were generated. These scatterplots are effectively a 'Mercator-like' projection of the parameters (in other words, equidistant values of $\mathbf{M}_{0}\left(\right.$ instead of $\left.\mathrm{T}_{0}\right)$ ) were displayed along the abscissa), with values of $\mathrm{M}_{0}$ ranging from 1.0 to 0 along the abscissa and Fr ranging from 0 to $1 \cdot 0$ along the ordinate. For subsequent inter-comparison of the land cover parameters, each of the summer pairs of AVHRR scenes, derived in terms of $\mathrm{M}_{0}$ and $\mathrm{Fr}$, were averaged into four summer composites.

\section{Results}

Figures 4(a) and $(b)$ respectively show the spatial relationship between Fr and $\mathrm{M}_{0}$ for the 1985/1994 AVHRR composite, with 1986/1993 percentage urban land cover statistics derived from Landsat TM coded in shades of grey. Although AVHRR and Landsat TM imagery dates do not match, the one-year difference between these images is not considered significant compared to the seven-year gap between the two Landsat TM images. In both scatterplots, pixels with the highest percentage urbanized tend to correspond to low values of $\mathrm{Fr}$ and $\mathrm{M}_{0}$, which suggests an increase in sensible heat flux in response to lower amounts of vegetation and increasing presence of reduced evaporating, non-transpiring surfaces in such pixels. At Fr $>0 \cdot 8$, the variance in $\mathrm{M}_{0}$ increases sharply in figure 4(a), possibly due to the differences in solar illumination of the soil due to shading by vegetation.

There are some noteworthy differences in the land cover parameters between figures $4(a)$ and $(b)$. First, the Fr values shown in figure 4(a) are uniformly elevated by about $0 \cdot 15$ NDVI in comparison to figure $4(b)$ (the 1994 summer composite) and both the 1988 and 1991 summer composites (not shown). This elevation in NDVI is an artifact of the subjective selection of $\mathrm{NDVI}_{\mathrm{s}}$, which was complicated in both 1985 AVHRR NDVI/T 0 scatterplots by pixel scatter at the flattened top of the warm edge. Second, an increase in the variance of $\mathbf{M}_{0}$ in figure 4(b) in comparison to figure 4(a) can be attributed to dampened soil from antecedent precipitation. Balling and Brazel (1988) noted that remotely-sensed surface measurements have a threeday 'memory' of antecedent precipitation. Daily precipitation measurements taken at State College reveal that there was 60 per cent more precipitation in the three days prior to scene overpass for the two 1994 AVHRR images than for the two 1985 images. Thus, analysis of temporal changes in the land cover parameters for a given location was made with an awareness of such sources of inter-scene variation. It should be noted that although small, the registration errors in the AVHRR images described in $\$ 2.1 .1$ are likely an additional source of inter-scene variation.

Using the 1985 AVHRR composite, linear relations between 1986 derived percentage urbanized and (separately) values of $\mathrm{T}^{*}$, Fr and $\mathrm{M}_{0}$ were tested for statistical significance, using an F-test (limited to pixels at least 25 per cent urbanized). 


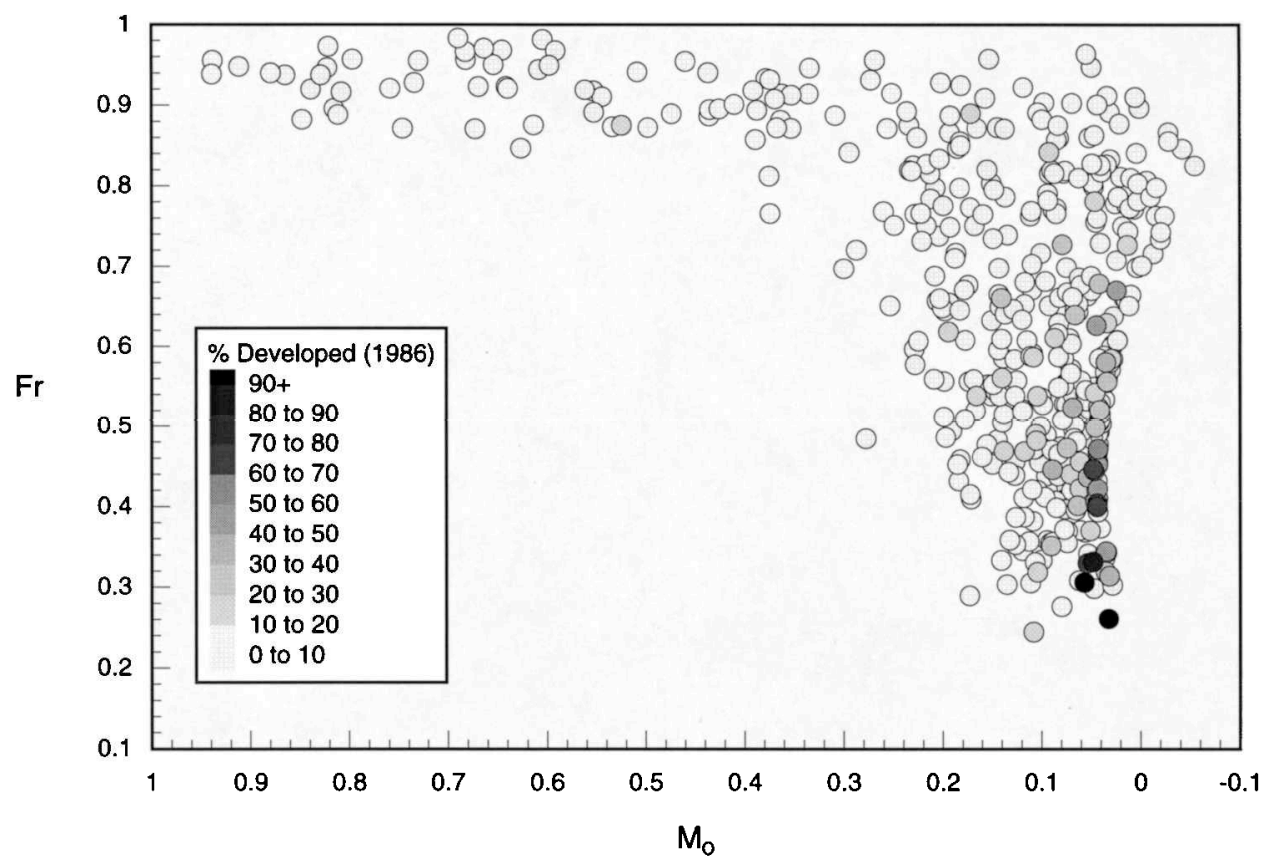

(a)

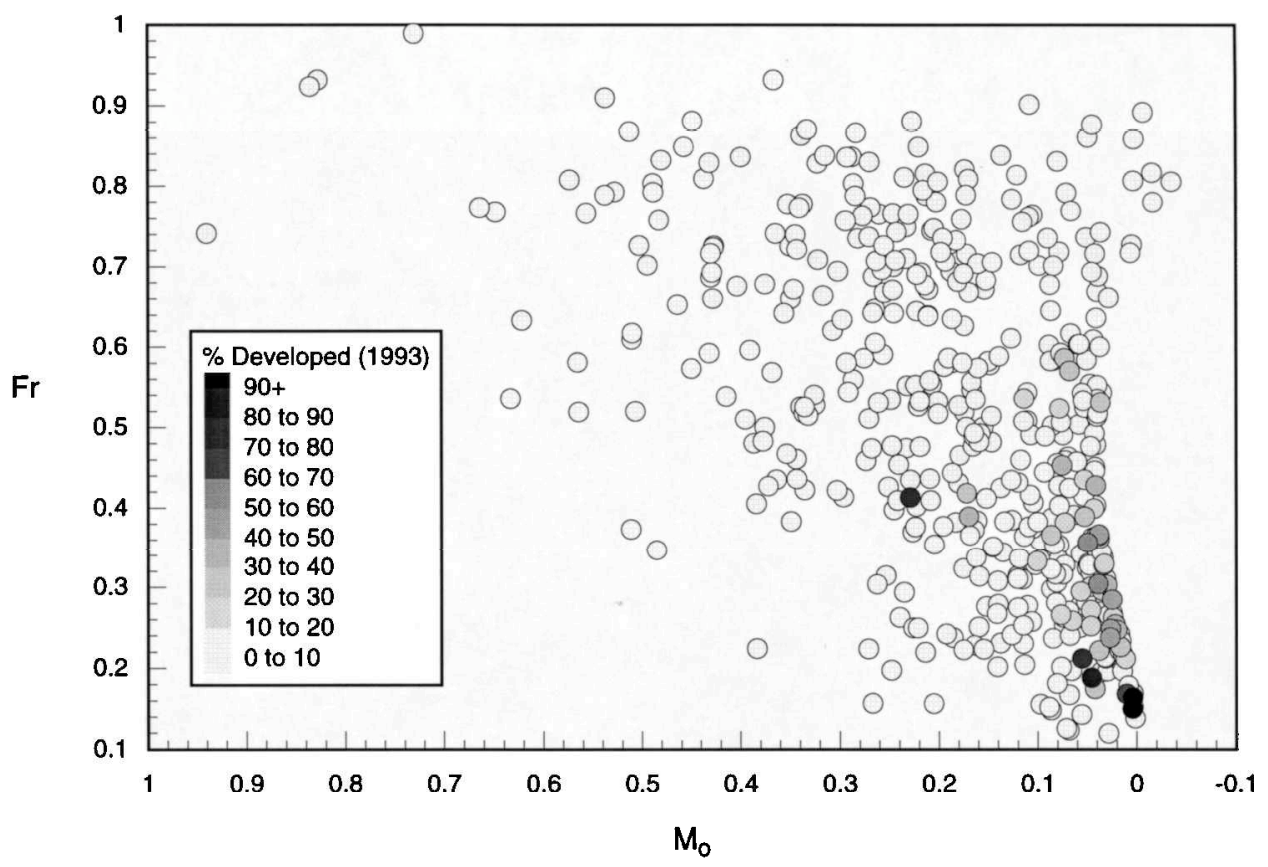

(b)

Figure 4. (a) Scatterplot of Fr versus $\mathrm{M}_{0}$ for a composite of the two 1985 AVHRR images. Percentage land cover classified as developed (urban), derived from a land cover classified 1986 Landsat-TM image, is coded for each pixel in shades of grey. (b) Scatterplot of Fr versus $\mathrm{M}_{0}$ for a composite of the two 1994 AVHRR images. Percentage land cover classified as developed (urban), derived from a land cover classified 1993 Landsat-TM image, is coded for each pixel in shades of grey. 
Significance was found between both $\mathrm{Fr}$ and percentage urbanized and $\mathrm{T}^{*}$ and percentage urbanized for the following linear regression relations.

$$
\begin{aligned}
& \mathrm{Fr}=0.554-0.003 \times \text { Percentage Development } \\
& \mathrm{T}^{*}=0.429+0.003 \times \text { Percentage Development }
\end{aligned}
$$

A lack of significance was found between $\mathrm{M}_{0}$ and percentage urbanized.

Figure 5 shows the Fr/T* attributes of three 4 by 4 AVHRR pixel subsets that were identified as predominantly forested, agricultural or urbanized within the study area (based upon the classified Landsat TM images). The centre of each ellipse denotes the average values of $\mathrm{T}^{*}$ and Fr, while the two ellipses surrounding each point represent the one and two standard deviation levels for the respective class. The forested pixel average, for example, were centred near the point $\mathrm{T}^{*}=0 \cdot 17, \mathrm{Fr}=$ $0 \cdot 8$, while agricultural and urban pixel averages were centred at higher values of $\mathrm{T}^{*}$ and lower values of Fr. The separation of urban areas from other land cover types in terms of $\mathrm{T}^{*}$ and Fr reflects the sensitivity of vegetation and surface radiant temperature to urban land use. High spatial resolution thermal infrared measurements by Nichol (1996) suggest that such distinctions, particularly between urban and vegetated pixels, yield similar separation in the surface radiant temperature response at the resolution of a city block. Although no single pixel in the study area was completely urbanized, by implication, fully urbanized surfaces would be found where $\mathrm{T}^{*}>0.9$ and $\mathrm{Fr}=0$ beyond the lower right corner of figure 5.

From the distribution of land cover types in the Fr/ $\mathrm{T}^{*}$ nomogram, a land cover index (LCI) is proposed in figure 6. The LCI allows the temporal process of urbanization to be quantified in terms of a location's starting point in the nomogram (representative of the mean influence of surrounding land cover) and the magnitude

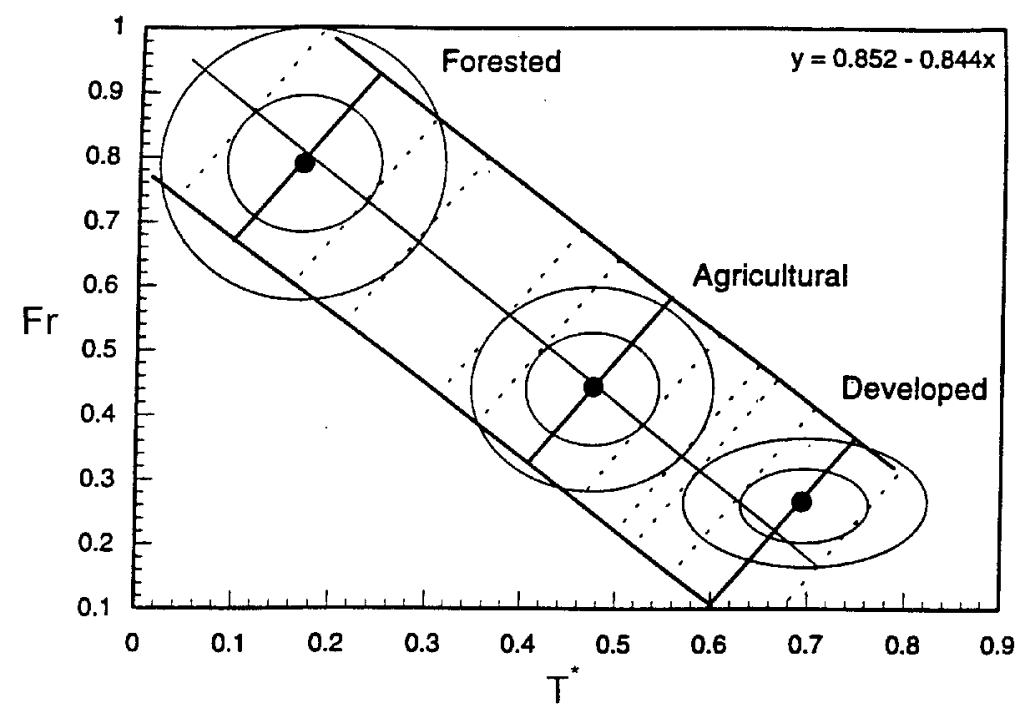

Figure 5. Nomogram of Fr and $\mathrm{T}^{*}$ showing the locations of predominantly forested, agricultural and developed (urban) classes. The dots indicate the mean positions of each class, and the rings mark the one and two standard deviation bounds for each class. The regression equation shown at the upper-right and plotted in the nomogram is the relationship between $\mathrm{Fr}$ and $\mathrm{T}^{*}$ for a composite of all AVHRR images. 


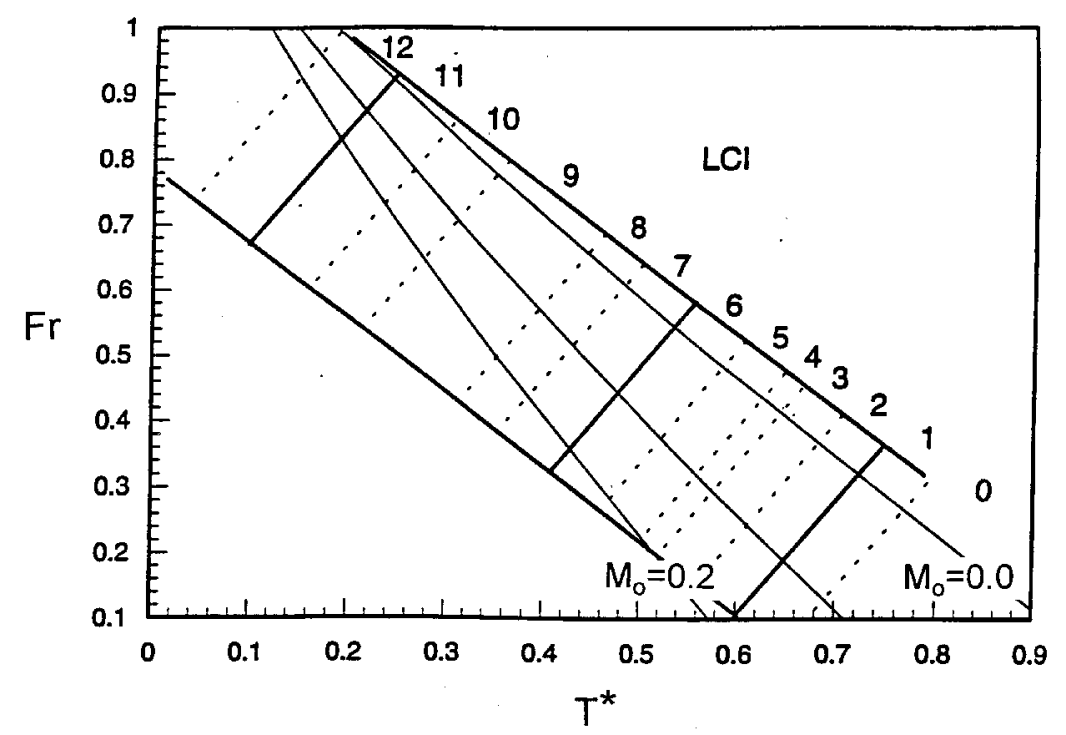

Figure 6. A proposed Land Cover Index (LCI), ranging from 0 (urban) to 12 (forested). The domain of each LCI value is bound by tangents to the standard deviation rings normal to the $\mathrm{Fr} / \mathrm{T}^{*}$ regression line and the 95 per cent prediction interval for the $\mathrm{Fr} / \mathrm{T}^{*}$ relations. $\mathbf{M}_{0}$ isopleths from the regional 'template' are overlaid.

of change (representative of the urbanization process, assuming that surrounding land cover remains relatively unchanged during the time period under consideration). LCI classes range from 0 (highly developed/urbanized) to 12 (highly forested). The boundaries between the LCI classes are determined by the furthest extent from the mean of the one and two standard deviation ellipses for the forested, agricultural and urban classes along the linear relations shown in figure 5 .

Using the overlays of LCI and $\mathrm{M}_{0}$ isopleths from figure 6, figures 7 and 8 show the temporal relations between the land cover parameters and urban land cover for two of the five pixels in the study area that underwent substantial urbanization (defined for pixels that underwent a minimum of 10 per cent increase in urbanization from 1986 to 1993 as defined by the two Landsat land cover classifications). The two temporal pixels trajectories shown are for two neighbourhoods in the vicinity of State College, whose locations are shown in figure 9. Between 1986 and 1993, the Park Forest neighbourhood experienced a 10 per cent increase in urbanization, while the Glenview neighbourhood, which experienced a 25 per cent increase in urban coverage. Given the differences in figures $4(a)$ and $4(b)$ an additional 'trajectory' of a composite of unchanged urban pixels is shown, which was derived from the mean of an ensemble of pixels that were at least 25 per cent urbanized in 1986 and underwent no further increase in urbanization by 1993. The composite is based on approximately twenty pixels that are in the immediate vicinity of the borough of State College. By definition, this control composite pixel should remain stationary in the nomogram in the absence of inter-scene variability.

\section{Discussion}

The difference in the $1985 \mathrm{Fr}$ and $\mathrm{M}_{0}$ values between the Park Forest and Glenview pixels in figures 7 and 8 is related to the dominant surrounding land cover 


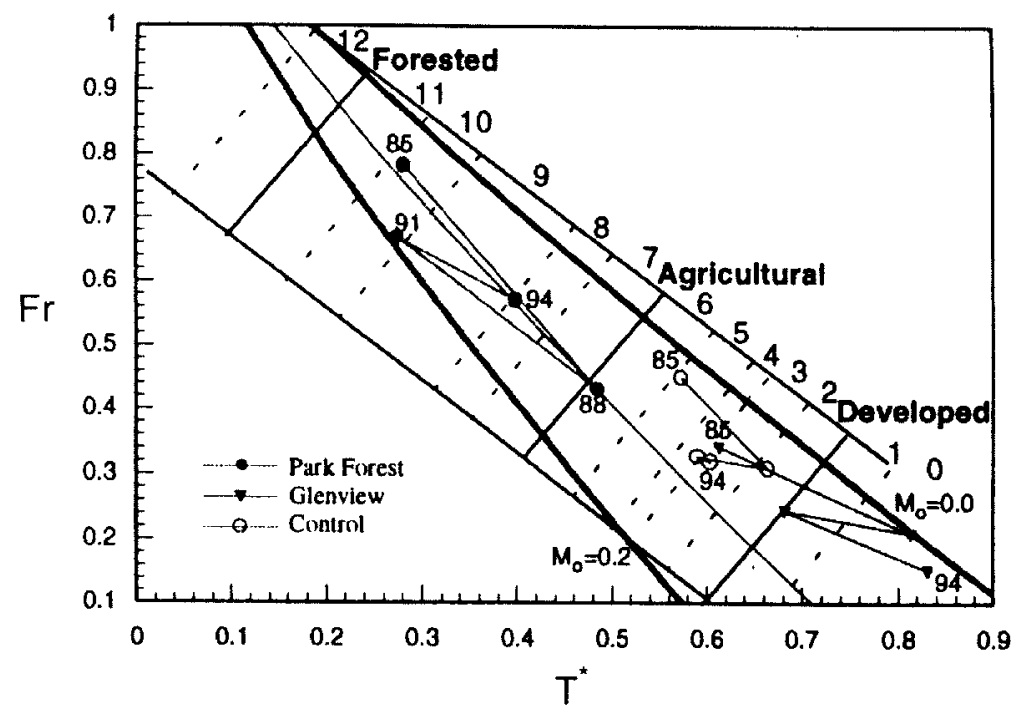

Figure 7. Temporal trajectories of two urbanizing pixels (corresponding to the Glenview and Park Forest neighbourhoods in State College, PA) between 1985 and 1994. A control composite 'trajectory' reveals remaining inter-scene variability after normalization.

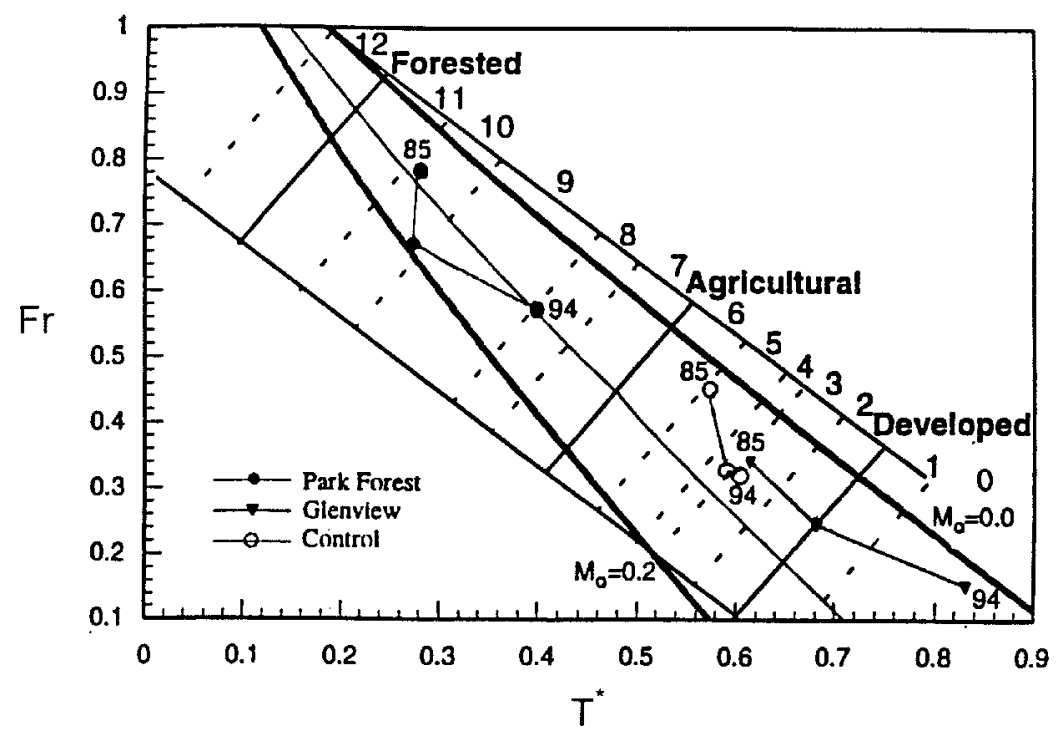

Figure 8. Temporal trajectories of two urbanizing pixels (corresponding to the Glenview and Park Forest neighbourhoods in State College, PA) between 1985 and 1994 EXCLUDING anomalous 1988 values. A control composite 'trajectory' reveals remaining inter-scene variability after normalization.

class for each pixel. Field observations confirmed that the natural surroundings of the Park Forest pixel were predominantly deciduous forest, while the Glenview pixel was surrounded by agricultural fields that were both fallow and in mixed use. A comparison of the 1986 and 1993 Landsat classifications shows that the make-up of surrounding land cover classes in these and all five analysed pixels remained 


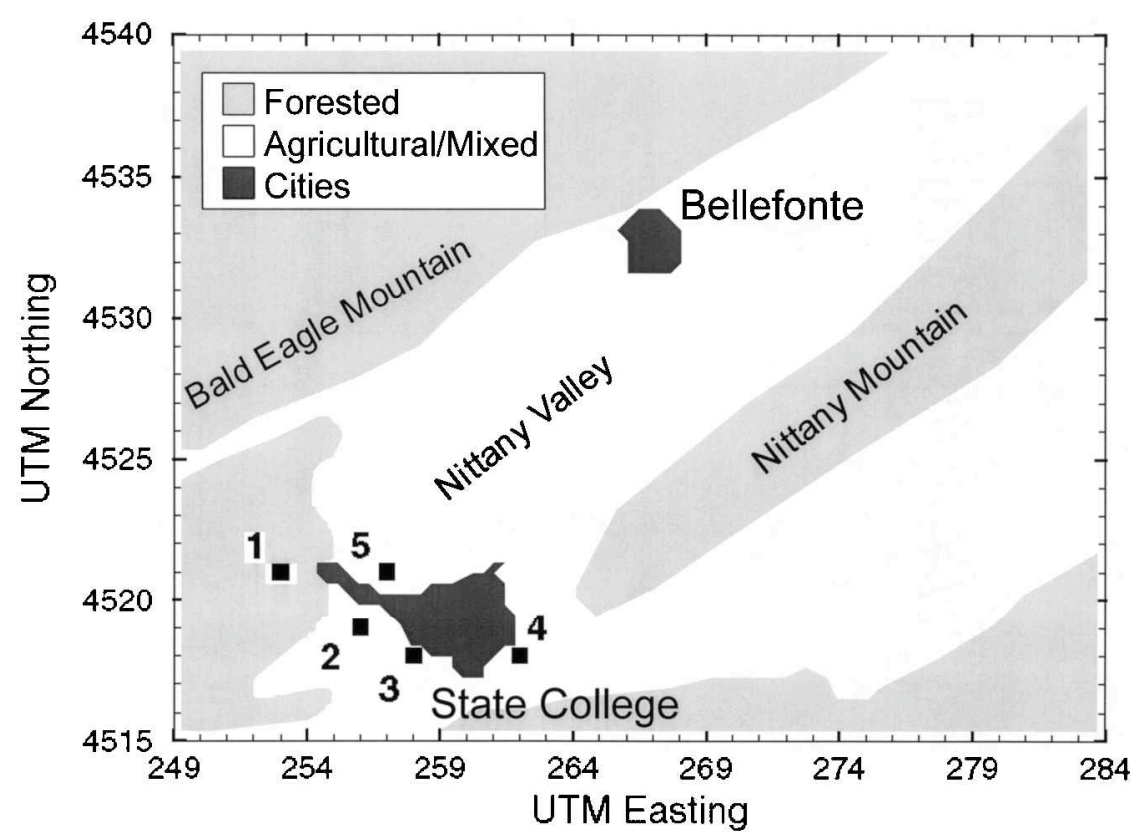

Figure 9. A map of the study area showing the location of pixels undergoing at least 10 per cent urban development between 1986 and 1993. Pixels numbers correspond to the following State College neighbourhoods: (1) Park Forest, (2) North Corl, (3) Glenview,

(4) Fairfield and (5) North College.

unchanged. Thus, urban development was the primary cause of the migration of the pixels in the $\mathrm{Fr} / \mathrm{T}^{*}$ nomogram.

As shown in figures 7 and 8, the magnitude of the change in LCI between 1985 and 1994 is approximately the same, about 3, for both the Park Forest (11 to 8) and Glenview ( $\sim 3.5$ to 0$)$ pixels. Yet, given that the Glenview pixel experienced 15 per cent more urban development than the Park Forest pixel, one might assume that the LCI change in the Glenview pixel should have been greater. It appears, though, that the similarity in the change in LCI is again related to the mean state of surrounding land cover. Given Glenview's predominantly agricultural and bare soil make-up in non-urban locations, the contrast between urban and surrounding locales is reduced in comparison to the stronger contrast between urban and densely vegetated surroundings in the Park Forest pixel. Such supposition is supported by Nichol (1996), who found that bare soil locations in Singapore can have even higher surface radiant temperatures than nearby urban structures under similar conditions of solar illumination.

Unfortunately, the persistence of inter-scene variability in spite of the normalization procedure, as shown in figures $4(a)$ and $(b)$ is also suggested by the temporal migration of the control pixel composite. The elevated value of $\mathrm{Fr}$ and reduced value of $\mathrm{T}^{*}$ for the 1985 control pixel composite (compared with the 1991 and 1994 positions) is related to exceptional variability in the location of pixels near the cusp of the pixel envelope for the two 1985 AVHRR scenes, which influenced the subjective selection of NDVI . The anomalous meteorological conditions associated with the warm, dry summer of 1988 are reflected in the lower value of Fr and higher value of $\mathrm{T}^{*}$ shown by the 1988 control pixel composite. Drought conditions effectively 
elongated the distribution of AVHRR composite pixels toward lower Fr and higher $\mathrm{T}^{*}$, as indicated in figure 7 by the jaggedness of both the Glenview and Park Forest temporal trajectories. In essence, drought conditions caused phenological stress that invalidated the $\mathrm{N}^{*} / \mathrm{Fr}$ relations, similar to the collapse in the accuracy of NDVI due to yellowing vegetation found by Paltridge and Mitchell (1990) during an Australian drought. Despite these sources of inter-scene variability, a well-defined migration toward lower Fr and higher $\mathrm{T}^{*}$ is evident between 1985 and 1994 for all five urbanizing pixels that were analysed, which is shown without the anomalous 1988 season in figure 8 .

Disregarding the 1988 data, the Glenview and Park Forest trajectories shown in figure 8 , as well as the trajectories of the other three pixels (not shown) that underwent substantial urbanization experienced consistent decreases in Fr in conjunction with increases in $\mathrm{T}^{*}$. However, they did not uniformly experience large decreases in $\mathbf{M}_{0}$. Thus, the analysis conditionally verifies the contention of the hypothesis that temporal changes in Fr are significantly associated with temporal changes in urban land cover.

The trajectories of the five urbanizing pixels analysed in the $\mathrm{Fr} / \mathrm{T}^{*}$ nomogram imply changes in regional-scale climate through an alteration in the rates of evapotranspiration. Using values of net integrated evapotranspiration derived from the SVAT model (Capehart 1996) and overlaid on the Fr/T* nomogram, the relations between these rates and urbanization were analysed. Table 1 shows the derived rates of evapotranspiration for the 1985 and $1994 \mathrm{Fr} / \mathrm{T}^{*}$ locations of the five analysed urbanizing pixels, as well as the magnitudes of LCI migration and percentage change in urban development between 1986 and 1993 (based on Landsat classification).

Table 1 suggests that daily rates of evapotranspiration are reduced by the urbanization process. This reduction appears to be related to either large changes in LCI or large changes in percentage urbanized, which suggest that the two measures are independently sensitive to surface energy repartitioning. LCI appears to correspond to large evapotranspiration changes when the index shifts substantially (e.g., the change from light density forest to light urban development for both the Fairfield and North College pixels). Percentage urbanized, on the other hand, tends to correspond best to substantial levels of urbanization $(>3$ per cent per year over an AVHRR pixel) (i.e., the Glenview pixel).

Table 1 also suggests that only modest changes in LCI are needed to cause large changes in evapotranspiration at lower values of LCI. This is related to the non-

Table 1. Daily evapotranspiration (ET) (in $\mathrm{Wm}^{-2}$ ) corresponding to pixel nomogram locations in 1985 and 1994 for all five pixels analysed in the study area.

\begin{tabular}{lcccccc}
\hline & $\begin{array}{c}1994 \\
\text { derived } \\
\text { ET }\end{array}$ & $\begin{array}{c}1985 \\
\text { derived } \\
\text { ET }\end{array}$ & $\begin{array}{c}1985-1994 \\
\text { ET } \\
\text { difference }\end{array}$ & $\begin{array}{c}\text { 1985-1994 } \\
\text { LCI } \\
\text { migration }\end{array}$ & $\begin{array}{c}\text { 1985-1994 } \\
\text { LCI } \\
\text { difference }\end{array}$ & $\begin{array}{c}\text { 1986-1993 } \\
\text { \% change } \\
\text { in urban land } \\
\text { cover }\end{array}$ \\
\hline Park Forest & 170 & 185 & -15 & 11 to 8 & -3 & 10.3 \\
Glenview & 96 & 125 & -29 & 3 to 0 & -3 & 25.3 \\
CONTROL & 125 & 140 & -15 & 5 to 3 & -2 & 0.0 \\
N. Corl & 125 & 140 & -15 & 5 to 2 & -3 & 10.6 \\
Fairfield & 125 & 155 & -30 & 7 to 2 & -5 & 10.6 \\
N. College & 125 & 155 & -30 & 8 to 3 & -5 & 11.9 \\
\hline
\end{tabular}


linear behaviour of the Bowen ratio (representative of surface energy partitioning) at low levels of $\mathrm{M}_{0}$. While $\mathrm{M}_{0}$ is not significantly related to changes in urban land cover, it can have an enormous effect on the pixel-averaged surface radiant temperature response based on the surrounding land cover type. The non-linear increase in the Bowen ratio at low values of $\mathrm{M}_{0}$ yields strong decreases in evapotranspiration and thus, even small changes in $\mathrm{M}_{0}$ at low values can reflect large changes in the surface energy budget due to urbanization. In once again comparing the Glenview and Park Forest pixels shown in figure 8, $\mathbf{M}_{0}$ is approximately the same in 1985 and 1994 for Park Forest, while it decreases from 0.05 to 0.015 in the Glenview pixel. This decrease is an important contributor to the $29 \mathrm{Wm}^{-2}$ decrease in evapotranspiration shown in table 1 .

The difference in the response of $\mathrm{M}_{0}$ between the Glenview and Park Forest pixels can be attributed to the texture of the urban surfaces themselves. Oke (1982) showed that vegetation typically covers $40-70$ per cent of urban areas, primarily in the form of lawns and ornamental trees that tend to dry out at a faster rate (and thus have a propensity for lower $\mathrm{M}_{0}$ ) than surrounding natural vegetation. From field observations of the two pixels, newly urbanized areas in the Park Forest pixel are embedded in relatively wooded areas, in contrast to the 'urban vegetation' manifested by scrubby shrubs, small, immature trees and cropped grass yards in the Glenview pixel. While this urban vegetation resulted in a reduced $\mathbf{M}_{0}$, it had minimal effect on Fr given the comparatively denser surrounding natural vegetation in each pixel. Thus, it should be no surprise that $\mathrm{M}_{0}$ is not significantly related to percentage urbanized, since urban vegetation is influenced by the contrast of surrounding land cover, landscape design and the age of the urban development. Despite this, values of $\mathrm{M}_{0}$ appear to offer an additional, independent measure of the local climate that can have important influences on evapotranspiration rates on the scale of an AVHRR pixel.

The essentially irreversible nature of urbanization implies that changes in $\mathrm{T}^{*}$ demonstrated in this research could be a contributor to long-term climatic change at regional and higher scales. Indeed, long-term changes in rates of evapotranspiration have been linked to urbanization over a period of several decades by Dow and DeWalle (1995). They identified significant negative trends in estimated evapotranspiration from 1927 to 1990 that resulted in regional increases in sensible heat fluxes of between 22-136 per cent for urbanizing watersheds. These potentially longlasting regional-scale climate impacts due to urbanization can be described by essentially permanent changes in land cover parameters Fr and $\mathrm{M}_{0}$. Such changes are a departure from the cyclic pattern in values of the parameters that have been observed in a nomogram of vegetation cover and surface radiant temperature and related to seasonal phenological change (Gillies and Carlson 1995).

\section{Conclusions}

Despite the coarse resolution of the AVHRR, it seems possible to determine, in part, changes in neighbourhood-scale surface radiant temperature values which are attributable to changes in urban land cover. Decreasing fractional vegetation cover due to urbanization is significantly related to changes in the surface microclimate, while the relationship between surface soil water content and urbanization is illdefined. However, given the sensitivity of surface soil water content to sensible heat flux at low values of $\mathrm{M}_{0}$, it is still a useful land cover parameter for the local assessment of climatic change. While the difference in $\mathrm{M}_{0}$ between the Park Forest 
and Glenview pixel is only about $0 \cdot 1$, a substantial differential in sensible heat flux (and surface radiant temperature) is implied at the latter location.

The land cover parameters offer researchers a physically-based characterization of the surface that is potentially useful $(a)$ as a descriptor of regional land use/land cover (LULC), and (b) as a quantitative surface boundary input into mesoscale models. Given that the land cover parameters are derived from the AVHRR, analyses using them can be performed both retrospectively (back to 1985) and efficiently (using pre-registered, pre-rectified, composited AVHRR products like the Global 1-km AVHRR data set (Eidenshink and Faundeen 1994)). Furthermore, recent results by Gillies et al. (1997) confirm that, under summertime conditions, the land cover parameters explain 90 per cent of the variance of the surface energy fluxes. Thus, the parameters should be considered in mesoscale modelling initializations, particularly for regions where LULC change has been pronounced during the past decade.

Further refinement of the land cover parameters and LCI could be obtained through higher spatial resolution satellite remote sensing over regions of significant urbanization (like the Glenview pixel). Such additional research could not only provide additional assessment of land cover parameters Fr and $\mathrm{M}_{0}$ and their potential applicability to urban climate studies, but also constitute a supplement to conventional classification types. Ultimately, it is hoped that the land cover parameters derived from the AVHRR can be used in concert with other parameters to monitor and detect urban-induced environmental changes from the neighbourhood to global-scale.

\section{Acknowledgements}

The authors wish to thank colleagues Dr Bill Capehart and David Ripley at Penn State University for their significant contributions to this study. The vital support of the Earth System Science Center and Department of Meteorology at Penn State University is greatly appreciated, as is the support of the National Climatic Data Center, NOAA, during the preparation of the manuscript. In addition, the assistance of the following individuals is gratefully acknowledged: Dr Rege Serinko, Department of Statistics, Purdue University; Dan Pennick, Chief Planner, Centre County Planning Office; and Dr Kevin Gallo, Office of Research and Applications, NOAA. This research was supported by the National Aeronautics and Space Administration (Contract NAGW-425), by the U.S. Department of Agriculture (Contract 58-32U4-8-27) and by EOS (Contract NAGW-2826).

\section{References}

Anderson, J. R., Hardy, E. E., Roach, J. T., and Witmer, R. E. 1976, A land use and land cover classification system for use with remote sensor data. U.S. Geological Survey Paper 964 (Washington, DC: USGPO, Department of the Interior).

Asrar, G., Fuchs, M., Kanemasu, E. T., and Hatfield, J. L. 1984, Estimating-absorbed photosynthetic radiation and leaf area index from spectral reflectance in wheat. Agronomy Journal 76, 300-306.

AuER, A. H., 1978, Correlation of land use and cover with meteorological anomalies. Journal of Applied Meteorology, 17, 636-643.

Balling, R. C., and Brazell, S. W. 1988, High resolution surface temperature pattern in a complex urban terrain. Photogrammetric Engineering and Remote Sensing, 54, 1289-1293.

Capehart, W. J., 1996, Issues Regarding the Remote Sensing and Modeling of Soil Moisture for Meteorological Applications. Ph.D. Dissertation, Penn State Department of 
Meteorology, 238 pp. Earth System Science Center Technical Report No. 96-005 (State College, Pennsylvania: The Pennsylvania State University).

Carlson, T. N., and Boland, F. E. 1978, Analysis of urban-rural canopy using a surface heat flux/temperature model. Journal of Applied Meteorology, 17, 998-1013.

Carlson, T. N., Dodd, J. K., Benjamin, S. G., and Cooper, J. N. 1981, Satellite estimation of the surface energy balance, moisture availability and thermal inertia. Journal of Applied Meteorology, 20, 67-87.

Carlson, T. N., Perry, E. M., and Schmugge, T. J. 1990, Remote estimation of soil moisture availability and fractional vegetation cover for agricultural fields. Agricultural and Forest Meteorology, 52, 45-69.

Carlson, T. N., Gillies, R. R., and Perry, E. M. 1994, A method to make use of thermal infrared temperature and NDVI measurements to infer surface soil water content and fractional vegetation cover. Remote Sensing Reviews, 9, 161-173.

Carlson, T. N., Gillies, R. R., and Schmugge, T., 1995, An interpretation of methodologies for indirect measurement of soil water content. Agricultural and Forest Meteorology, 77, 191-205.

Centre County Planning Office, 1992, Centre County Existing Land Use, 1990 (Bellefonte: Centre Country Planning Office).

Che, N., and Price, J. C., 1992, Survey of radiometric calibration results and methods for visible and near infrared channels of NOAA-7,9, and 11 AVHRRs. Remote Sensing of Environment, 41, 19-27.

Choudhury, B. J., Ahmed, N. V., Idso, S. B., Reginato, R. J., and Daughtry, C. S. T., 1994, Relationship between evaporation coefficients and vegetation indices studied by model simulations. Remote Sensing of Environment, 50, 1-17.

Dow, C. L., and Dewalle, D. R., 1995, Long-term trends in evaporation on urbanizing and forested watersheds in Pennsylvania. In Proceedings of the Conference on Water Management in Urban Areas, Houston, TX. (Bethesda, Maryland: American Water Resources Association), pp. 305-312.

Eidenshink, J. E., and FAundeEn, J. L., 1994, The $1 \mathrm{~km}$ AVHRR global land data set: first stages in implementation. International Journal of Remote Sensing, 15, 3443-3462.

Emery, W. J., Brown, J., and NowaK, Z. P., 1989, AVHRR image navigation, summary and review. Photogrammetric Engineering and Remote Sensing, 55, 1175-1183.

Fisher, A., 1994, Seasonal variation of vegetation indices. Remote Sensing of Environment, 48, 220-230.

Gilabert, M. A., Gandí, S., and Meliá, J., 1996, Analyses of spectral-biophysical relationships for a corn canopy. Remote Sensing of Environment, 55, 11-20.

Gillies, R. R., and CARLSON, T. N., 1994, A physically based modeling approach for including remotely derived measurements in the study of land use change. In Effects of HumanInduced Changes on Hydrologic Systems, Proceedings of the American Water Resources Association, Annual Summer Symposium, Technical Publication Series (TPS-94-3) (Bethesda, Maryland: American Water Resources Association), pp. 27-34.

Gillies, R. R., and CARlson, T. N., 1995, Thermal remote sensing of surface soil water content with partial vegetation cover for incorporation into climate models. Journal of Applied Meteorology, 34, 745-756.

Gillies, R. R., Cui, J., Carlson, T. N., Kustas, W. P., and Humes, K. S., 1997, Verification of the 'Triangle' method for obtaining surface soil water content and energy fluxes from remote measurements of NDVI and surface radiant temperature. International Journal of Remote Sensing, 18, 3145-3166.

Goward, S. N., Cruickshank, G. D., and Hope, A. S., 1985, Observed relation between thermal emission and reflected spectral radiance of a complex vegetated landscape. Remote Sensing of Environment, 18, 137-146.

Henry, J. A., Dicks, S. E., Wetterquist, O. F., and Roguski, S. J., 1989, Comparison of satellite, ground-based, and modeling techniques for analyzing the urban heat island. Photogrammetric Engineering and Remote Sensing, 55, 69-76.

Hodgson, M. E., and Shelley, B. M., 1994, Removing the topographic effect in remotely sensed imagery. ERDAS Monitor, 6, 4-6.

Humes, K. S., Kustas, W. P., and Schmugge, T. J., 1995, Effects of soil moisture and spatial resolution on the surface temperature/vegetation index relationships of a semiarid 
watershed. In Preprint Volume of the Conference on Hydrology, Proceedings of the American Meteorological Society Annual Meeting, Dallas, TX, 15-20 January 1995 (Boston, Massachusetts: American Meteorological Society), pp. 147-151.

Idso, S. B., Schmugge, T. J., Jackson, R. D., and Reginato, R. J., 1975, The utility of surface temperature measurements for remote sensing of soil water studies. Journal of Geophysical Research, 80, 3044-3049.

Lynn, B., and CARLSON, T. N., 1990, A stomatal resistance model illustrating plant versus external control of transpiration. Agricultural and Forest Meteorology, 52, 5-43.

Nemani, R. R., and Running, S. W., 1989, Estimation of regional surface resistance to evapotranspiration from NDVI and Thermal-IR AVHRR data. Journal of Applied Meteorology, 28, 276-284.

NiCHOL, J. E., 1996, High-resolution surface temperature patterns related to urban morphology in a tropical city, a satellite-based study. Journal of Applied Meteorology, 35, 135-146.

NOAA, 1988, Data extraction and calibration of TIROS-N NOAA radiometers. NOAA Technical Memorandum NESS 107 (Washington, DC: USGPO, Department of Commerce).

OKe, T. R., 1982, The energetic basis of the urban Heat Island. Quarterly Journal of the Royal Meterological Society, 108, 1-24.

Paltridge, G. W., and Mitchell, R. M., 1990, Atmospheric and viewing angle correction of vegetation indices and grassland fuel moisture content derived from NOAA/AVHRR. Remote Sensing of Environment, 31, 121-135.

PRICE, J. C., 1984, Land surface temperature measurements from the split window channels of the NOAA-7 Advanced Very High Resolution Radiometer. Journal of Geophysical Research, 89, 7231-7237.

Price, J. C., 1990, Using spatial context in satellite data to infer regional scale evapotranspiration. I.E.E.E. Transactions on Geoscience and Remote Sensing, 28, 940-948.

Rотн, M., Oке, T. R., and EmerY, W. J., 1989, Satellite derived urban heat islands from three coastal cities and the utilization of such data in urban climatology. International Journal of Remote Sensing, 10, 1699-1720.

Richards, J. A., 1993, Remote Sensing Digital Analysis, An Introduction (New York: Springer-Verlag).

Stull, R. B., 1988, An Introduction to Boundary Layer Meterology (Dordrecht: Kluwer Academic). 